\title{
Effect of Fc $\gamma$ RIIa and Fc $\gamma$ RIIIa Gene Polymorphism on Treatment Response and Overall Survival in Diffuse Large B Cell Lymphoma
}

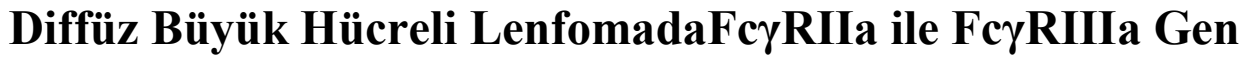 Polimorfizminin Tedaviye Cevabı ve Toplam Ömür Süresi Üzerine Etkisi}

\author{
Oktay Bilgir ${ }^{1}$, Sabri Batun ${ }^{2}$ \\ ${ }^{1}$ Sağlık Bilimleri Üniversitesi Bozyaka Eğitim Ve Araştırma Hastanesi Hematoloji Kliniği Bozyaka/izmir \\ ${ }^{2}$ Dicle Üniversitesi Tıp Fakültesi Biyokimya Anabilim Dalı Diyarbakır
}

Dergiye Ulaşma Tarihi:12.10.2017 Dergiye Kabul Tarihi:30.11.2017 Doi: 10.5505/aot.2018.65882

\section{ÖZET}

Amaç: FçRIIaile FçRIIIa gen polimorfizmi bulunan diffüz büyük B hücreli lenfomalı olguların R-CHOP tedavisine yanıtını araştırmak amacıyla çalışma planlandı.

Yöntem ve Gereçler: CD20+ diffüz büyük B hücreli lenfoma tanılı 90 hastanın (47 Kadın,43 Erkek) FcyRIIa ve Fc $\gamma$ RIIIa gen polimorfizmi qPCR ile bakıldı. Hastalara 6 kez R-CHOP tedavisi verildikten sonra tedaviye yanıt ve toplam ömür süreleri değerlendirildi.

Bulgular: Fc $\gamma$ RIIa ile Fc $\gamma$ RIIIa gen polimorfizmi bulunan olgularda tedaviye yanıt ve toplam ömür süresinin diğerlerinden istatistiksel olarak farklı olmadığı saptandı.

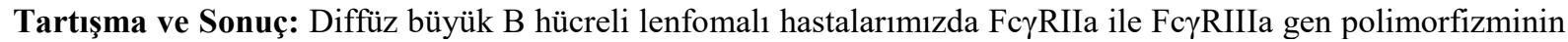
tedaviye yanıt ve toplam ömür süreleri üzerine etkisi olmadığı̆ görülmüştür. Malign filloid tümörler veya epitelyal tümör içeren filloid tümörler, onkoplastik cerrahi teknikleri ile negatif cerrahi sınırla rezeke edilebilir. Böylece, filloid tümörlerde onkolojik ve kozmetik olarak başarılı sonuçlar elde etmek mümkündür.

Anahtar Kelimeler: Diffüz büyük B hücreli lenfoma, tedaviye yanıt, Fc $\gamma$, RIIa, Fc $\gamma$ RIIIa, gen polimorfizm

\begin{abstract}
Introduction: A study was planned to investigate the response of diffuse large B-cell lymphomas with Fc $\gamma$ RIIa and Fc $\gamma$ RIIIa, gene polymorphism to R-CHOP therapy.

Methods: Total 90 patients (47 female and 43 male) with CD20 + diffuse large B-cell lymphoma diagnosed with Fc $\gamma$ RIIa and Fc $\gamma$ RIIIa gene polymorphism by qPCR technique. The response was assessed by treatment with six cycles of R-CHOP treatment and the overall survival of cases diagnosed with polymorphism was calculated. Results: There was no statistically significant difference in response to treatment between Fc $\gamma$ RIIa and Fc $\gamma$ RIIIa gene polymorphism and other cases.
\end{abstract}

Discussion and Conclusion: Diffuse large B-cell lymphoma with Fc $\gamma$ RIIa and Fc $\gamma$ RIIIa gene polymorphism has no effect on to overall survival as a result of treatment response.

Keywords: diffuse large B cell lymphoma, response to treatment, Fc $\gamma$, RIIa, Fc $\gamma$ RIIIa, gene polymorphism

\section{GIRIŞ}

Diffüz büyük B hücreli lenfoma non-Hodgkin Lenfomalarının en sik rastlanan alt grubudur. $\mathrm{Bu}$ hastalara önceden sadece kemoterapi verilirken CD20+ olgularda tedaviye Rituximab eklenmesiyle ciddi anlamda tedaviye yanıt ve toplam ömür süresi açısından önemli iyileşmeler elde edilmiştir $(1,2)$.

Rituksimab bu etkisini B lenfositlerinde apoptozise, komplemana bağımlı sitotoksiteye

Adress for correspondence: Oktay Bilgir, SBÜ Bozyaka EAH Bozyaka/İzmir İzmir - Türkiye e-mail: oktaybilgir@gmail.com

Available at www.actaoncologicaturcica.com

Copyright $\mathbb{C}$ Ankara Onkoloji Hastanesi ve Fc $\gamma$ Reseptörünü kullanarak antikor bağımlı sitotoksisiteye yol açarak göstermektedir $(3,4)$. Yine bu monoklonal antikor, CD20+ hücrelerin yüzeyinde $\mathrm{Fc \gamma}$ Reseptörünü bulunduran makrofaj ve natural killer hücreleri ile malign B lenfositleri arasında köprü görevi yaparak etkisini göstermektedir (5). Fc $\gamma$ RIIIa reseptörü daha çok natürel killer hücreleri üzerinde ekspresse olurken FcyRIIa reseptörü nötrofil ve makrofajlar üzerinde bulunurlar. 
Fc $\gamma$ RIIIa genomik polimorfizminin 158. pozisyonunda valin $(\mathrm{V})$ veya fenilalanin (F) oluşuna göre 3 alleli bulunmaktadır (6). FcrRIIa reseptörünün 131.pozisyonunda histidin $(\mathrm{H})$ veya Arginin (R) oluşuna göre de 3 allel oluşturmaktadır (9).Follikuler lenfoma olgularında, Fc $\gamma$ RIIIa reseptörünün valin homozigos olgularında (V/V), fenilalanin homozigos olgularına göre (F/F) Rituksimab tedavisine yanıtının daha iyi olduğu iddia edilmiştir. Tedaviye cevabın iyi olmasının nedeninin Fc $\gamma$ RIIIa reseptörüne natürel killer hücrelerinin daha yüksek afinitesi olduğu gösterilmiştir (7). Yine Fc $\gamma$ RIIIa V/V allelinin Waldenström Makroglobulinemisinde Rituksimab tedavisine yanıtı iyileştirirken KLL'de (kr. lenfositer lösemi) tedaviye cevabı kötüleştirmektedir (12). Bir araştırmada da Fc $\gamma$ RIIIa V/V fenotipinin Rituksimab kombinasyonlu tedavilere yanitı daha iyi olduğunu, ancak bu durumun toplam yaşama yansımadığını bildirmişlerdir (14). Bir başka çalışmada da folliküler lenfomalı Fc $\gamma$ RIIa $\mathrm{H} / \mathrm{H}$ homozigos fenotipi olan olgularda $H / R$ veya $\mathrm{R} / \mathrm{R}$ fenotiplerine göre rituksimab monoterapisine daha iyi tedavi yanıtı olduğunu bildirmişlerdir (9).

$\mathrm{Bu}$ fenotiplerin herbirinin in vitro olarak IgG molekülüne afiniteleri farklı olduğundan bu allel değişikliğinin tedaviye yanıtı belirleyip belirlemediğini hastalarımızda çalışmayı planlandık.

\section{MATERYAL VE METOT}

Diffüz büyük B hücreli lenfoma tanısı alan 90 hasta çalışmaya dahil edildi. Hastaların rutin hemogram ve biyokimya tetkikleri yapıldıktan sonra Ann-Arbor'a göre evreleme yapıldı ve IPI (uluslararas1 prognostik indeks) skoru hesapland. Olgulara ortalama 6 kez 3 haftalık aralıklarla R-CHOP tedavisi uygulandi. Rituksimabilk gün $375 \mathrm{mg} / \mathrm{m}^{2}$ 4-6 saatlik infüzyonla verildikten sonra 2.gün siklofosfamid $750 \mathrm{mg} / \mathrm{m}^{2}$, doksorubisin 50 $\mathrm{mg} / \mathrm{m}^{2}$, vinkristin $1,4 \mathrm{mg} / \mathrm{m}^{2}$ İV verildi. 5 gün süreyle prednizon $100 \mathrm{mg} / \mathrm{m}^{2}$ oral verildi. 6 kezbu tedavi verildikten sonra 3 ay aralıklarla kontrole çağrıldı.

Fc $\gamma$ RIIa ve FcyRIIIa polimorfizmi için 4 cc EDTA'lı kandan DNA ekstrakte edildikten sonra $-80^{\circ} \mathrm{C}^{\prime}$ ye kondu. Fc $\gamma$ RIIa ve Fc $\gamma$ RIIIa polimorfizmi için Light Cycler üzerinde RTPCR (Roche Diagnostic, Basel, Switzerland) reaksiyonu sonrasında analiz yapıldı. RT-PCR, Fc $\gamma$ RIIa H131R ve Fc $\gamma$ RIIIa V158F toolset (specific primers and fluorescen to ligonucleotide probes) ve Fast Start DNA Master Hybridization Probe Kit (Genes-4U, Neftenbach, Switzerland) kullanıldı. RT-PCR protokolü başlangıç denaturasyonu sırasıyla, 2 dk. $95^{\circ} \mathrm{C}$ sonra 40 siklüs $95^{\circ} \mathrm{Cde} 10$ saniye, $56^{\circ} \mathrm{C}^{\prime}$ de 10 saniye, $72^{\circ} \mathrm{C}$ 'de 1 dakika olarak yapıld1. Eritme protokolü $95^{\circ} \mathrm{C} 30$ saniyede, $70^{\circ} \mathrm{C}$ 'de 1 dakika bekleme süresiydi. Devaml 1 floresan okumas $10-99^{\circ} \mathrm{C}$ aralığında ve saniye başına $0.1^{\circ} \mathrm{C}$ isı yükseltilmesi uyguland.

\section{İstatistik}

Veriler SPSS 15 'e göre analiz edildi. Olgular Mann-Whitney $U$ testi ile gen allel gruplar1 karşılaştırıldı. Ömür süreleri Kaplan-Meier tekniği ile hesaplandı. Bütün analiz sonuçları yorumland 1 ve $\mathrm{p}$ değerinin $0.05^{\prime}$ 'den daha küçük olması anlamlı kabul edildi.

\section{BULGULAR}

Çalışmaya toplam 90 hasta alındı. Hastaların klinik özellikleri tablo 1'de gösterildi. Hastaların çoğu 50 yaşının üstündeydi (\%80). Erkek/Kadın oranı birbirine yakındı (\%48\%52). Ann-Arbor Evrelemesine göre Evre 3-4 vakaların \%79'unu oluşturmaktaydı. IPI (uluslararası prognostik indeks) göre 0-2, \%53 iken 3-5 \%37 civarında bulundu.

Tablo 1: Hastaların Klinik Özellikleri

\begin{tabular}{|c|c|c|}
\hline Özellik & Sayı (n:90) & Yüzde \\
\hline Yaş & & \\
\hline$<50$ & 18 & 20 \\
\hline$\geq 50$ & 72 & 80 \\
\hline Cins & & \\
\hline Erkek & 43 & 48 \\
\hline Kadın & 47 & 52 \\
\hline Evre & & \\
\hline $1-2$ & 19 & 21 \\
\hline $3-4$ & 71 & 79 \\
\hline IPI & & \\
\hline $0-2$ & 48 & 53 \\
\hline $3-5$ & 42 & 37 \\
\hline
\end{tabular}

Hastaların fenotiplerine bakıldığında FcyRIIIa reseptörünün V/V alleli 12, V/F 26 ve F/F de 8 hastada saptandi. Her 3 allelde de tedaviye yanıt açısından farklılık izlenmedi. 
Aynı şekilde FcyRIIa reseptörünün fenotipleri H/H 18 hastada, H/R alleli 24 olguda ve R/R'da 4 vakada saptandı. Tedaviye yanıt açısından her 3 allelde de fark izlenmedi (Tablo 2). Şekil 1' de Kaplan Meier tekniği ile olguların toplam ömür sürelerin bakıldığında benzer eğriler görülmektedir.

Tablo 2: Hastaların Fc $\gamma$ RIIIa ve Fc $\gamma$ RIIa fenotipleri ve tedaviye yanitları

\begin{tabular}{|l|l|l|l|l|}
\hline Fc $\gamma$ RIIIa & & & & \\
\hline & V/V(n:12) & V/F(n:26) & F/F(n:8) & $\mathrm{p}$ \\
\hline CR & $7(\% 58)$ & $20(\% 73)$ & $5(\% 63)$ & 0.77 \\
\hline PR & $2(\% 17)$ & $3(\% 15)$ & $1(\% 12)$ & \\
\hline SD & $2(\% 17)$ & $1(\% 5)$ & $1(\% 12)$ & \\
\hline PD & $1(\% 8)$ & $2(\% 7)$ & $1(\% 12)$ & \\
\hline Fc $\gamma$ RIIa & & & & \\
\hline & H/H(n:18) & H/R(n:22) & R/R(n:4) & $\mathrm{p}$ \\
\hline CR & $13(\% 71)$ & $17(\% 77)$ & $3(\% 75)$ & 0.65 \\
\hline PR & $1(\% 5)$ & $2(\% 9)$ & $1(\% 25)$ & \\
\hline SD & $2(\% 12)$ & $1(\% 5)$ & 0 & \\
\hline PD & $2(\% 12)$ & $2(\% 11)$ & 0 & \\
\hline
\end{tabular}

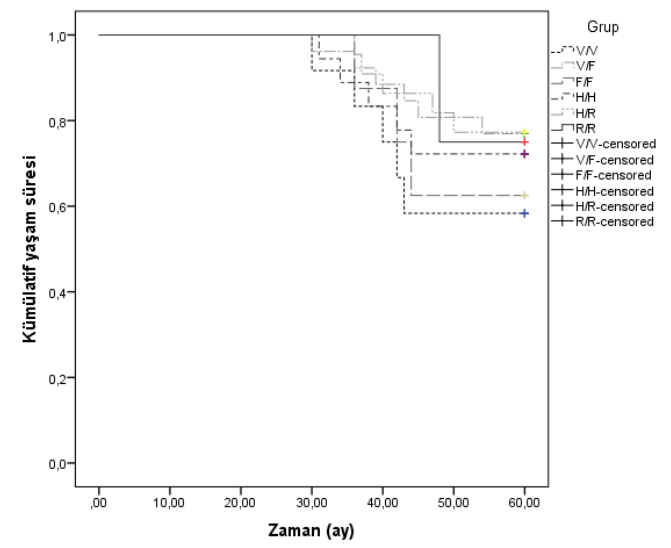

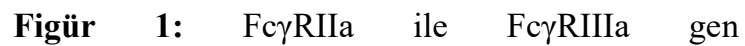
polimorfizmlerinin kümülatif ömür süreleri üzerine etkisi.

\section{TARTIŞMA}

Monoklonal antikor tedavisinin lenfomada kullanılmasıyla birlikte farklı lenfoma türlerinde tedavi yanıtın farklı olduğu gözlenmiş ve hastaların tedavi öncesi durumlarının yanıtı etkileyebileceği düşünülmüştür (9). Özellikle rituksimabın tedaviye girmesiyle antikora bağımlı hücresel sitotoksisitenin (ADCC) aktivitesini Fc $\gamma \mathrm{R}$ yoluyla yaptığı düşünülmektedir. FçRIIa ile FcyRIIIa genlerinde görülebilecek olan polimorfizmlerin diffüz büyük $B$ hücreli lenfomalı olgularda rituksimabın etkisi değişebileceği düşünülerek yapılan bir çalışmada Fc $\gamma$ RIIIa V/V fenotipinde R-CHOP tedavisinin daha iyi olduğu rapor edilmiştir $(22,23)$. Ancak başka bir çalışmada bu etkinin istatistiksel anlamı olmadığını bildirilmiştir $(26,28)$. Başka bir çalışmada da bu hastalığın tedaviye yanıtı ile Fc $\gamma$ Rallelleri arasında bir ilgi saptanmamıştır (14). Bizim hastalarımızda hem tedaviye yanıtta hem de toplam ömür süreleri üzerinde $F c \gamma R$ allellerinin etkisi olmadığını saptadık. Yapılan birçok çalışmada Fc $\gamma$ RIIIa $\mathrm{V} / \mathrm{V}$ polimorfizminin $\mathrm{F} / \mathrm{F}$ fenotipine göre yanıtının daha iyi olduğu, yine Fc $\gamma$ RIIa $\mathrm{H} / \mathrm{H}$ fenotipinin $\mathrm{R} / \mathrm{R}$ fenotipine göre yanıtlarının daha iyi olduğunu bildiren yayınlar mevcuttur $(8,9,12)$. Ancak daha sonraki birçok araştırıcı, bahsedilen bu fenotiplerin hastalıssız yaşam üzerine etkisi olmadığını bildirdiler (20-28). Ayrıca daha önceki çalışmalardaki araştırıcılar belirtilen fenotiplerde yanıtın nasıl iyi olduğuna dair bir yorumda bulunmamışlardır.

Çalışmamızda hem tedaviye yanıt hem de toplam ömür sürelerinin değerlendirilmesi sonucu hem Fc $\gamma$ RIIa da $\mathrm{H} / \mathrm{H}$ fenotiplerinin $\mathrm{R} / \mathrm{R}$ 'ye veya $\mathrm{H} / \mathrm{R}$ 'ye hem de FcyRIIIanın V/V fenotipinin $V / F$ ya da $F / F$ allelerine üstünlügünü saptamadık. Çalışmamızda incelediğimiz tüm fenotiplerin tedaviye yanıtta ve toplam ömür süreleri üzerinde etkisi olduğunu gözlemedik.

Sonuç olarak, yaptığımız çalışmada FcyRIIa ile FcyRIIIa gen polimorfizminin diffüz büyük B hücreli lenfomanın tedavisinde kullanılan R-CHOP tedavisine alınan yanıtta fark izlenmedi. $\mathrm{Bu}$ sonuç lenfomadaki malign hücrelerin ortadan kaldırılmasında rolü olan ADCC nin esas olarak FcyRIIa ile FcyRIIIa reseptörlerinin üzerinden gerçekleşmediğini düşündürmektedir.

Financial disclosure: We did not receive financial support for this article.

Conflict of interest: In the article, there is no conflict of interest in any.

\section{REFERANSLAR}

1. Tilly H, Vitolo U, Walewski J, da Silva MG, Shpilberg O, André M, Pfreundschuh M andDreyling M; ESMO GuidelinesWorkingGroup: Diffuselarge B celllymphoma (DLBCL): ESMO Clinical Practice Guidelines for diagnosis, treatment 
and follow up. Ann Oncol 23 (Suppl 7): vii78 vii82, 2012.

2. Molina A: A decade of rituximab: Improving survival outcomes in non Hodgkin's lymphoma. Annu Rev Med 59: 237 250, 2008.

3. Plosker GL, Figgitt DP. Rituximab: a review of itsuse in non-Hodgkin's lymphoma and chronic lymphocytic leukaemia. Drugs 2003; 63:803-43.

4. Jazirehi AR, Huerta-Yepez S, Cheng G, Bonavida B. Cellular and molecular signal transduction pathways modulated by rituximab (rituxan, anti-CD20 mAb) in non-Hodgkin's lymphoma:implications in chemosensitization and therapeutic intervention. Oncogene 2005; 24:2121-43.

5. van der Pol WL, Jansen MD, Sluiter WJ, van de Sluis B,Leppers-van de Straat FG, Kobayashi T, et al. Evidence for non-random distribution of Fcg receptor genotype combinations.Immunogenetics 2003;55:240-6

6. Koene HR, Kleijer M, Algra J, Roos D, von dem Borne AE, deHaas $\mathrm{M}$, et al. FcgRIIIa $158 \mathrm{~V} / \mathrm{F}$ polymorphismin fluences the binding of $\mathrm{IgG}$ by natural killer cell by FcgRIIIa, independently of FcgRIIIa-48L/R/H phenotype. Blood 1997; 90:1109-14.

7. Dall'Ozzo S, Tartas S, Paintaud G, Cartron G, Colombat P,Bardos P, et al. Rituximab-dependent cytotoxicity by natural killer cells: influence of FCGR3A polymorphism on the concentration-effect relationship. Cancer Res 2004; 64:4664-9.

8. Cartron G, Dacheux L, Salles G, Solal-Celigny P, Bardos P,Colombat P, et al. Therapeutical activity of humanized anti-CD20 monoclonal antibody and polymorphism in IgGF creceptor FcgRIIIa gene. Blood 2002; 99:754-8.

9. Weng W-K, Levy R. Twoimmunoglobulin G fragment $\mathrm{C}$ receptor polymorphisms independently predict response to rituximab in patients with follicular lymphoma. J ClinOncol2003; 21:3940-7.

10. Boetcher S, Pott C, Ritgen M, Hiddeman W, Unterhalt M,Kneba M. EvidenceforFcgRIIIAindependent rituximab effector mechanisms in patients with follicular lymphoma treated with combined immunochemotherapy. Blood 2004; 104:170a[abstract].

11. Carlotti E, Palumbo GA, Oldani E, Acerboni S, DiRaimondoF, Cortelazzo S, et al. Bone marrow bcl2/IgH+ cells at diagnosis and not FcgRIIIA polymorphism predict response in follicular nonHodgkin's lymphoma patients treated with sequential CHOP and rituximab. Blood 2005; 106:289a[abstract].

12. Treon SP, Hansen M, Branagan AR, Verselis S, Emmanouilides C, Kimby E, et al. Polymorphisms in FcgRIIIA(CD16) receptor expression are associated with clinical response to rituximab in Waldenstrom's macroglobulinemia. J Clin Oncol 2005; 23:474-81.

13. Farag SS, Flinn IW, Modali R, Lehman TA, Young D, Byrd JC.FcgRIIIa and FcgRIIa polymorphisms do not predict response to rituximab in B-cell chronic lymphocytic leukemia. Blood2004; 103:1472-4.

14. Kim DH, Jung HD, Kim JG, Lee JJ, Yang DK, Park $\mathrm{YH}$, et al.FcgRIIIa gene polymorphisms may correlate with response to frontline R-CHOP therapy for diffuse large B-cell lymphoma. Blood 2006; 108:2720-5.

15. Cheson BD, Horning SJ, Coiffier B, Shipp MA, Fisher RI,Connors JM, et al. Report of an international workshop to standardize response criteria for non-Hodgkin's lymphomas.NCI Sponsored International Working Group. J Clin Oncol1999; 17:1244-53.

16. Zhuang Y, Xu W, Shen $\mathrm{Y}$ and Li J: Fc $\gamma$ receptor polymorphisms and clinical efficacy of rituximab in non Hodgkin' lymphoma and chronic lymphocytic leukemia. Clin Lymphoma Myeloma Leuk 2010;10: 347352.

17. Ravetch JV andBolland S: IgGFcreceptors. AnnuRevImmunol 19: 275 290, 2001.

18. Parren PW, Warmerdam PA, Boeije LC, Arts J, Westerdaal NA, Vlug A, Capel PJ, Aarden LA and van de Winkel JG: On the interaction of IgG subclasses with the low affinity Fc gamma RIIa (CD32) on human monocytes, neutrophils, andplatelets. Analysis of a functional polymorphism to human IgG2. J Clin Invest 1992; 90: 15371546.

19. de Haas M, Koene HR, Kleijer M, de Vries E, Simsek S, van Tol MJ, Roos D and von dem Borne AE: A triallelic $\mathrm{Fc}$ gamma receptor type IIIA polymorphism influences the binding of human IgG by NK cell Fc gamma RIIIa. J Immunol 1996;156: 29482955.

20. Hatjiharissi E, Hansen M, Santos DD, Xu L, Leleu X, Dimmock EW, Ho AW, Hunter ZR, Branagan AR, Patterson CJ, et al: Geneticlinkage of Fc gamma RIIa and Fc gamma RIIIa and implications for their use in predicting clinical responses to CD20 directed monoclonal antibody therapy. Clin Lymphoma Myeloma 2007; 7: 286290.

21. Warmerdam PA, van de Winkel JG, Vlug A, Westerdaal NA and Capel PJ: A single amino acid in the second Ig like domain of the humanFc gamma receptor II is critical for human $\mathrm{IgG} 2$ binding. J Immunol 1991;147: 1338 1343.

22. Ahlgrimm M, Pfreundschuh M, Kreuz M, Regitz E, Preuss KD and Bittenbring J: The impact of Fc $\gamma$ receptor polymorphisms in elderly patients with diffuse large B cell lymphoma treated with CHOP with or without rituximab. Blood 2001;118: 4657 4662.

23. Kim DW, Jung HD, Kim JG, Lee JJ, Yang DH, Park YH, Do YR, Shin HJ, Kim MK, Hyun MS and Sohn SK: FCGR3A gene polymorphisms may correlate with response to frontline $\mathrm{R}$ CHOP therapy for diffuse large B cell lymphoma. Blood 2006;108: 27202725.

24. Cheson BD, Horning SJ, Coiffier B, Shipp MA, Fisher RI, Connors JM, Lister TA, Vose J, Grillo López A, Hagenbeek A, et al: Report of an international workshop to standardize response criteria for non Hodgkin's lymphomas. NCI Sponsored International Working Group. J ClinOncol1999;17: 1244.

25. Rohtagi S, Gohil S, Kuniholm MH, Schultz H, Dufaud C, Armour KL, Badri S, Mailliard RB and Pirofski LA: Fc gamma receptor 3A polymorphism and risk for HIV associated crypto $\neg$ coccal disease. M Bio 2013;4: e00573 e00613.

26. Mitrovic Z, Aurer I, Radman I, Ajdukoviç R, Sertiç $\mathrm{J}$ andLabar B: FCgammaRIIIA and FCgammaRIIa 
polymorphisms are not associated with response to rituximab and $\mathrm{CHOP}$ in patients with diffuse large $\mathrm{B}$ cell lymphoma. Haematologica2007;92: 998999.

27. Fabisiewicz A, Paszkiewicz Kozik E, Osowiecki M, Walewski J andSiedlecki JA: Fc $\gamma$ RIIA and Fc $\gamma$ RIIIA polymorphisms do not influence survival and response to rituximab, cyclophosphamide, doxorubicin, vincristine, and prednisone immunochemo-therapy in patients with diffuse large B cell lymphoma. LeukLymphoma2011;52: 1604 1606.
28. Váróczy L, Zilahi E, Gyetvai A, Kajtár B, Gergely L, Sipka S andIllés A: Fc gamma receptorIIIa polymorphism and gene expression profile do not predict the prognosis in diffuse large $\mathrm{B}$ cell lymphoma treated with R CHOP protocol. Pathol Oncol Res 2012;18: 4348 . 